\title{
Indeterminate or Unknown Menopause
} Status

National Cancer Institute

\section{Source}

National Cancer Institute. Indeterminate or Unknown Menopause Status. NCI Thesaurus.

Code C159630.

The menopause status is unknown. 